\title{
Project-based learning opportunities in a digital environment: research on the naming of tourist destinations
}

\author{
Svetlana Bylkova ${ }^{1}$, Lubov Goncharova ${ }^{2}$, Ella Kitanina $^{2 *}$, and Igor Kudryashov ${ }^{3}$ \\ ${ }^{1}$ Don State Technical University, 344003, Rostov-on-Don, Russia \\ ${ }^{2}$ State Institute of the Russian Language named after A.S. Pushkin, 117485, Moscow, Russia \\ ${ }^{3}$ Southern Federal University, 344007, Rostov-on-Don, Russia
}

\begin{abstract}
The study is devoted to a problem that has not been sufficiently studied in relation to the field of education, namely, the problem of projectbased learning in the digital environment. To solve this problem, education is considered as a contemporary phenomenon that allows the use of IT technologies and thus expands the opportunities of students both in terms of their mobility and the access to the educational process from anywhere in the world, and in terms of attracting intellectual, creative and technical resources. It was supposed that project-based learning in the digital environment has considerable prospects for students to gain professional skills, develop creative ideas, and introduce research methods into the business environment. As an example, the sociolinguistic research in the field of tourism was used. The project study conducted by the students is due to the growing interest of Russians in traveling around the country, but at the same time it showed the unpreparedness of the advertising and information base and proved that appealing to the promotion of domestic tourism, specialists should understand that today it is necessary to transform approaches to advertising tours and excursion routes. Thus, the implementation of joint student projects in the digital environment, covering sociolinguistic research and further work of specialists in the tourism industry, carried out on their basis on information and advertising support for tourist and excursion activities, will allow implementing project-based training as an important part of the practice-oriented educational process. In such projects, interdisciplinary interaction and inter-university cooperation can be implemented.
\end{abstract}

\section{Introduction}

The purpose of this study is to identify and describe the possibilities of project-based learning in a digital environment.

The tasks of the work are reflected in the logical sequence of the description of the scientific and practical problems solved by the authors: 1) to determine the current possibilities of university education in the digital environment in terms of interactivity and

\footnotetext{
* Corresponding author: ella kitanina@mail.ru
} 
the introduction of new methods in the educational process; 2) to illustrate the process of introducing the theoretical knowledge obtained by students into practical activities within the project method; 3 ) to show the methodological possibilities of getting out of the theory into the practical activity of a specific business sphere (in this case, in the field of tourism) with the involvement of a complex of studied disciplines and interuniversity interaction; 4) to describe the use of the project method on a specific example.

The features of learning in the digital environment are flexibility (in terms of the choice of time, place, level of complexity, quality of information) [1,2], accessibility (it is permissible to conduct classes anywhere in the world where there is an Internet connection) $[3,4,5]$, mass (the probability of reaching a larger number of interested students), the rate of assimilation of the material (the ability to perform the task at a comfortable pace for students), repetition (it is permissible to re-use the materials in the recording at any time), the ability to perform several actions in parallel (getting education remotely and locally $[6,7]$; getting education during work or leisure). It is precisely because of its features that project-based learning in the digital environment attracts more and more users around the world and encourages teachers to use the capabilities of computer technologies in teaching.

The effectiveness of the use of learning in the digital environment has been considered in a number of works by Russian [8,9] and foreign authors [10] scientists and teachers have studied the potential of interactive learning. For example, the problem of the effectiveness of distance learning was considered when carefully planning the student's activities, but only general aspects were studied in detail: the structuring of the course, the interactivity of the educational process, the implementation of mandatory feedback, and the motivation of students. At the same time, there is very little research on highly specialized learning goals, although it is thematic developments that allow to introduce new teaching methods that modern university education requires. In particular, the development of projects gives students the opportunity to accumulate their knowledge not only in one subject area, but also to attract a complex of disciplines, going beyond one narrow direction.

The pandemic, on the one hand, suspended the usual course of the educational process, on the other - revealed many «weak points» of personnel training, gave a boost not only to the technical development of educational resources, but also allowed university teachers to creatively approach the professional training of students, invite colleagues from other organizations, including teachers-employers, to cooperate, and carry out joint projects in a digital environment. In addition, the period of forced isolation also showed the risks of business. In particular, the most vulnerable areas of business have become obvious, for which, nevertheless, personnel training continues to be conducted. Tourism has become one of these areas. Outbound tourism was almost completely stopped. Many companies have refocused on the domestic market, and the demand for Russian destinations has begun to grow. However, the unexpected interest of Russians in traveling around the country showed not only the unpreparedness of the tourist infrastructure, but also the lack of an advertising and information base. Appealing to the promotion of domestic tourism, experts should understand that today it is necessary to transform the approaches to the promotion of tours and sightseeing routes.

In this regard, combining research conducted in the digital environment by specialists from different fields will expand the possibilities of the tourism industry. In this case we are talking about inclusion in the field of training "Tourism business", which is implemented on the basis of the Faculty of Service and Tourism of the Don State Technical University (Rostov-on-Don), the sociolinguistic research methods, which are carried out on the basis of the Department of General and Russian Linguistics of «The State Institute of the Russian Language named after A. S. Pushkin» (Moscow) and on the basis of the Department "Documentation and language communication" of the Don State Technical University (Rostov-on-Don). 
The emergence and implementation of this project is due to a number of factors that determined the relevance of the described project training.

1. Images of different regions are formed on the basis of descriptions of natural features, location, regional attractions-folklore, mythology, symbolism, etc., which largely determines the transmission brightness specifics of this tourist object. Hence the unusual names of tours and sightseeing routes, designed to form or accentuate certain emotional markers of places.

2. However, the perception and evaluation by consumers of such naming services require study, research and, accordingly, the introduction of project methods of training in the digital environment, which allows to train the largest number of professionally competent specialists.

\section{Materials and Methods}

This study is based on the assumption that project-based learning in the digital environment has considerable prospects: first, it allows to get an education not only independently from any activity, but also away from the immediate educational environment; second, it makes it possible to focus the targeted attention on obtaining certain knowledge, skills and competencies. In addition, project-based training makes it possible to move from theory to practical activity in a specific business area (in this particular case, in the field of tourism) with the involvement of a complex of studied disciplines and inter-university interaction, which will be shown later.

The methodological basis of the research are the works on linguistic problems of advertising, naming and copywriting [11], works in the field of research of the advertising communication linguistic features in the tourism sector [12]. The range of works that turned out to be necessary in terms of ensuring the theoretical reliability of the study also includes studies on the theory and practice of sociolinguistics and pragmalinguistics [13, 14]. A significant segment of the theoretical platform is formed by scientific works on pedagogy, methods of teaching humanities. We have used the method of analysis when working with scientific and educational literature, when considering and selecting models of subjectlanguage integration that are relevant for teaching the language of the specialty, language communication in the professional sphere; the method of analogy, which allowed us to compare the data obtained on organizational, content and technological solutions used in teaching at the Faculty of «Service and Tourism» $[15,16]$. Empirical methods were also used - a method of observation, a method of comparing data used in domestic and foreign practice of project training, as well as in the study of the results of pedagogical experiments, a method of questioning and survey. The experimental method was used during the constructing, forming and control stages of the pedagogical experiment. The statistical method was used in the collection and processing of the results of linguistic and socio-cultural surveys and tests, in the qualitative analysis of practical tasks and students' works, as well as in the analysis of the results of the experiment, attracted by specialists of the Pushkin State Institute of the Russian Language.

Great opportunities for conducting such experiments are also provided by the mental map (intelligence map), which is now an effective means of organizing educational activities. British psychologist Tony Buzen, who had discovered the method, provided the opportunity to transfer a large amount of material to an electronic environment, to make accessible and visualized a large scheme that not only activates students' activities, but also teaches them a creative and innovative approach to learning [17]. This technology allows to display any information, namely processes, events, ideas, thoughts, etc. The graphic form develops thinking, since both hemispheres of the brain become involved. Today, intelligence maps are formed and used in various types of training programs. One can use the online resources Mindomo, MindMeister, Coggle, Diagrams, XMind, MindManager, and others as functional 
constructors of smart maps. The creation and use of intellectual maps helps to structure and visualize information, as well as the process of thinking, generating ideas, which is very important for project methods in the educational process. Thus, project training allows students to form independent thinking, creative approach, about the development of students in the process of educating the activity norms, correcting the professional position on the basis of reflecting one's own experience and practical implementing the activities.

We agree with N. G. Shved, who defines designing as the activity of creating projects (development schemes) for the implementation of various types of activities. «Project training encourages the ability to understand their activities from the standpoint of a value approach, to goal-setting, to self-education and self-organization, to synthesize and summarize information from different sources, the ability to make choices and make decisions. With the introduction of the project-based learning method, which is based on research and creative activities, it becomes possible to deepen and consolidate the knowledge gained in different disciplines, to fulfill the social orders of society. The results of such activities are the development and deepening of professional competencies, understanding and adopting new approaches to their professional activities, etc.» [18].

The research material is the advertising names of tours created in Russian. Performed by students and teachers of the Pushkin State Institute of the Russian Language the research (Stage 1) will allow students of Don State Technical University to develop a tourist product for the domestic market (Stage 2), which proves the need to use sociolinguistic methods in the field of tourism.

A group of the 3-rd year students (30 students) of the Pushkin State Institute of the Russian Language who study in the framework of the discipline «Sociolinguistics», and students of the "Documentation and archival science" field of study in the framework of the discipline "Copywriting" carried out the project work and investigated the sociolinguistic characteristics of a tourist destination as an attractive object. The goal of the first stage of the project was a pilot study of the acceptance of tourist destinations and excursion sites by target audits. At the second stage of the project work, the results obtained and the recommendations developed were transmitted to the students of the 3-rd year of Don State Technical University in the direction of training «Tourism» for developing the tourist product of the domestic market.

In the process of conducting research on the sociolinguistic characteristics of a tourist destination as an attractive object, students of the Pushkin State Institute of the Russian Language and students of the Don State Technical University conducted an online survey using Google forms (110 respondents were surveyed), and for developing the questionnaires, intelligence maps were compiled, which allowed to determine the range of questions. So, questions and answer options were formed around the keywords, on the basis of which the questionnaire was developed (see Fig. 1, 2).

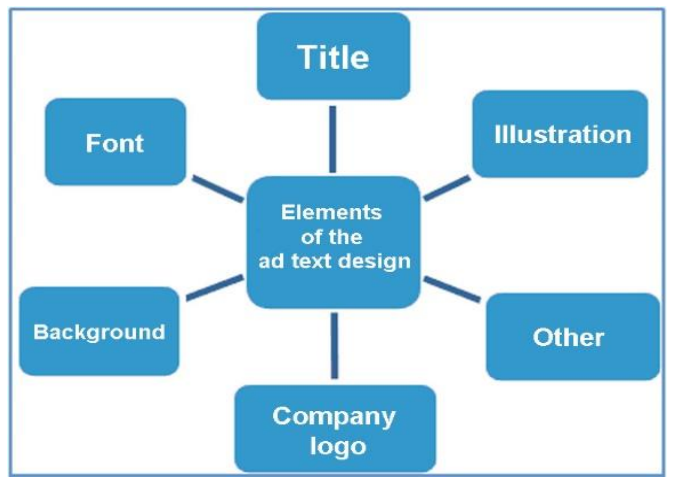

Fig.1. A fragment of the intelligence map. 


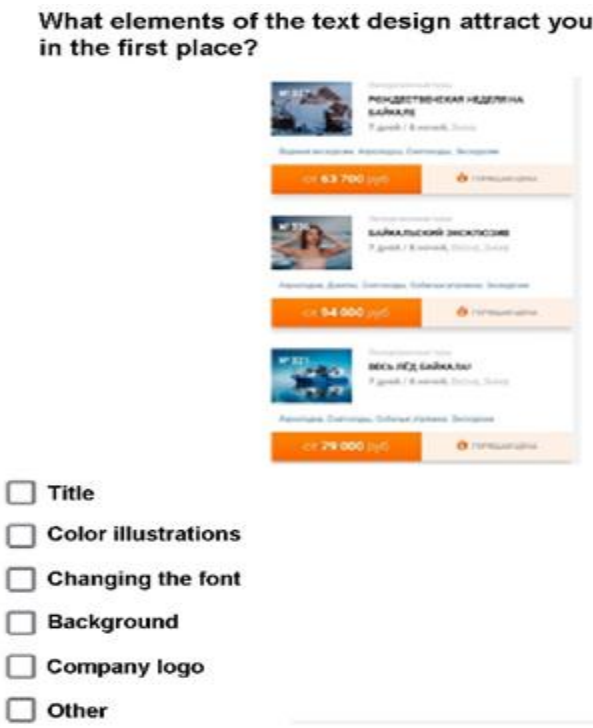

Fig. 2. Questionnaire developing.

\section{Results}

Turning to the tourism industry, it should be noted that it is the social order that largely determines the specialists' current intension to develop domestic tourism, and the university graduates' ability to fill in the gaps in the consumer market in the field of tourism can largely reorient tourist flows and help implement strategic programs for the development of tourism in the regions.

The analysis showed a lack of research in the field of naming and copying in the field of tourism, a lack of information about consumer preferences in terms of perception of the proposed tourist product. The sphere of tourism in the discursive, sociolinguistic aspects is described in less detail [19], very little Russian research has been conducted.

Such activities are particularly promising in the contemporary digital environment, which allows for extensive research. «The creators of company names try to use any constructive element, resources of motivation and persuasiveness in subtext meanings, in those meanings that are born due to cultural, historical and psychological associations. As an argument for attracting customers, any ringing name is used, and even with a national or cultural-specific halo» [20]. However, markers, like other artificial formations, are the domain of (individual or group) taste preferences. If the informative component contained in the name of this travel agency corresponds to reality, then a certain amount of bad taste could be ignored.

Marking designations are essentially names intermediate between proper names and common names. Labels perform special pragmatic functions in advertising. The specificity of advertising communication as a special sphere of communication consists in purposeful expanding the addressee's knowledge about the objects of advertising, forming a positive attitude towards it, fixing its image in the consumer's memory and creating the necessary forms of behavior. The text has both a cognitive function (transmitting specific information) and a pragmatic function (imposing a certain opinion on the addressee and encouraging certain actions). Copywriters adapt to the addressee's knowledge system in such a way as to provide the easiest entry of the necessary information, taking into account that the addressee has a certain amount of linguistic and non-linguistic knowledge. This knowledge largely 
determines the fate of incoming information. It is either perceived or rejected as incompatible with the addressee's cognitive system.

Since the purpose of the described project is to determine the most successful names of tourist objects from the point of view of travelers, as well as to find out how the sociolinguistic characteristics of a tourist object affect its attractiveness in a tourist's eyes, in accordance with this goal, a survey was built (see Fig. 3).

What elements of the text design attract your attention in the first place?

110 responses

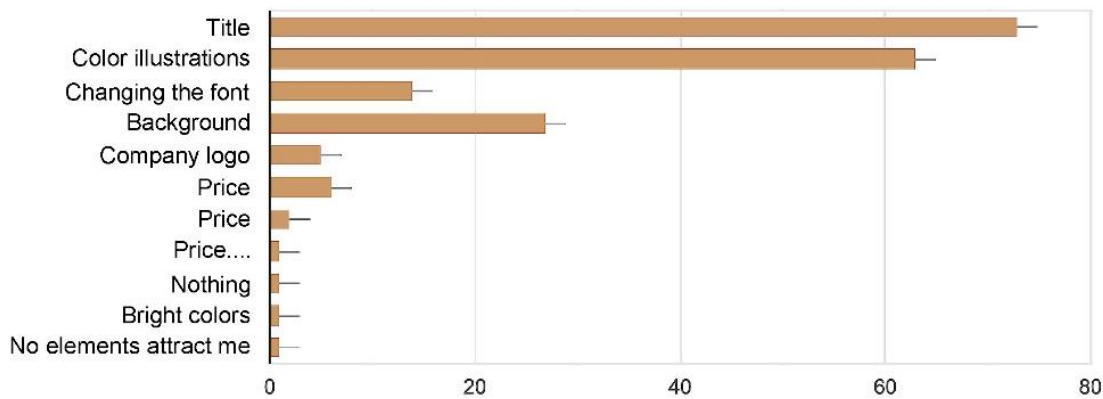

Fig. 3. Tourist destination names.

The answers confirmed the well-known opinion that the title of the advertising text most attracts the reader's attention (note that the title somehow appeals to the topic of the tour or the name of the tourist destination) (see Fig. 3), and the most important information in the content of the text is determined by the price and name of the tour (see Fig. 4).

What is the first thing you pay attention to in the content of the text?

110 responses

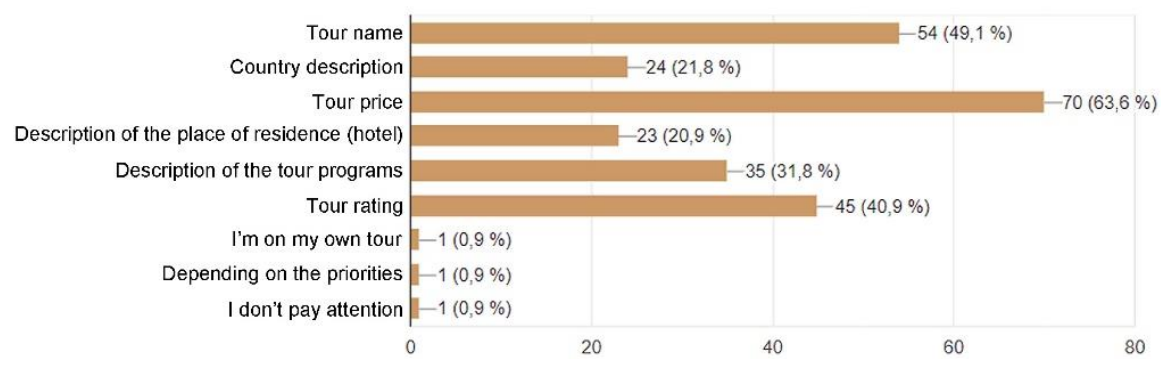

Fig. 4. Tour attractiveness rating.

The survey participants also identified the naming that implies the possibility of getting acquainted with something unknown, while at the same time not wanting to follow a celebrity's «authoritative» opinion (see Fig. 5).

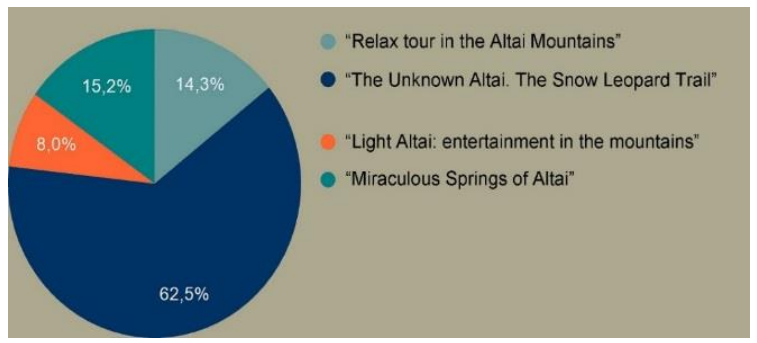

Fig. 5. Selecting the tour nominations-1. 
Surveys have also shown that the traditions and legends of cities have a certain «demand» among tourists. Thus, it can be a good material for increasing the popularity of the place among travelers (see Fig. 6).

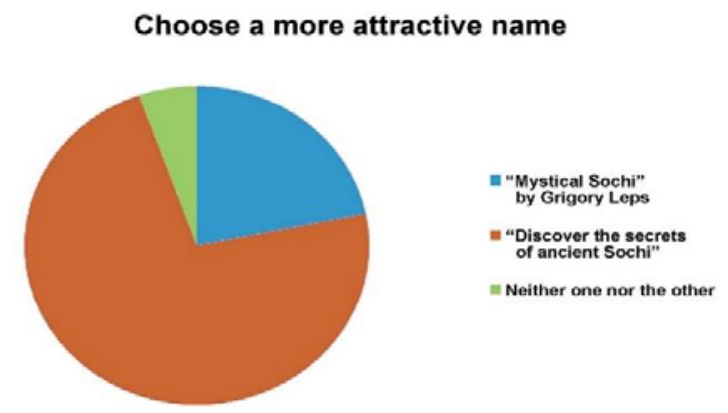

Fig. 6. Selecting the tour nominations-2.

The projects of the first stage performed by students and teachers of the State Institute of the Russian Language University made it possible to move on to the project activities of the second stage in the Don State Technical University, creating a tourist product and its advertising support.

\section{Discussion}

The discussion of the most effective teaching methods and project opportunities was conducted by many scientists, representatives of linguodidactics, but such close attention to the multidimensional possibilities of project learning in the digital environment has not been observed before. For example, the multicomponent multi-functional professional model of the teacher in the system of distance learning at the beginning of the XXI century contains a system of qualification characteristics for each of its components: 1) general pedagogical design of the language learning environment, 2) pedagogical design of remote resources that fill it, 3) management of a remote learning resource, 4) development of scenarios for remote learning resource components, 5) network individual consultation, 6) coordination of the work of a virtual working group, 7) network control and expert evaluation of learning results [21].

More than two decades have passed, and today the knowledge acquisition in the digital environment is closely intertwined with the multidimensional context of social reality. In connection with the needs of the new time, «education should be built by analogy with the process of socialization, taking into account all the features and functions of education as a phenomenon. Taking into account all the political, economic and other processes in the contemporary society, through cognitive-semantic perception - this is the only way to get involved in the digital learning environment. In addition, the use of individual and group mental maps (see above) contributes to a deeper understanding of the material when teaching students at the university and prepares the mental base of culture as the basis for multi-layer project-based learning. Thus, education in the digital environment is formed through information obtained through the development of human intelligence and, as a result, the progressive improvement of various intellectual experiences in the process of mastering and cognizing the world around him and all the elements that make up this world, including himself. Experts also mention the risks associated with the introduction of digital technologies by higher education as an integral part of digital pedagogy. The digital environment, which creates many opportunities for the educational process, has very significant drawbacks, which both teachers and students themselves cannot fail to note. O. 
V. Filippova writes about these problems: «Few people doubt the need to digitalize the educational process, but among scientists and practical teachers, the methodological issues related to this process do not lose their sharpness and relevance. Among them, we should note some that are important for teaching communication-oriented disciplines that solve the problems of student's communicative training in higher education: first, is it possible and effective to completely replace traditional forms of educational communication with forms mediated by computer technologies; second, what is the optimal combination of forms of computer-mediated communication and traditional group and interpersonal educational communication» [22]. According to the authors of this article, project-based teaching methods can compensate for the lack of feedback and provide communicative contact between the project participants, their live interaction with the teacher-supervisor, as well as active involvement of students' creative abilities in solving project tasks.

The second most discussed problem is the competent design of a new toponymic policy within the framework of naming in the field of service and tourism, since it is strategically necessary that this direction is promising not only within the framework of a single state, but also in the world service and tourism. The semantic directions that have already received some development in the names created both in the most ancient period and in the post-Soviet period become important. Nowadays these issues are gaining a new direction and discussion in the framework of research on linguistic landscapes conducted in different countries and allow to regulate cultural and language policy and develop the tourism industry, creating a positive image of a tourist destination [23, 24].

\section{Conclusion}

Thus, the project-based learning system makes it possible to combine the didactic tasks of pedagogy with the actual problems of professionally oriented learning, while using the digital environment, which became an integral part of the educational process during the pandemic. These are the issues requiring further discussion and elaboration, careful experiments, and consistent conclusions.

1. Project activity is practically oriented and allows to create cross-cultural complex projects of cross-interaction between students of various specialties, giving the opportunity to exchange experience and acquire new knowledge.

2. The conducted experiment confirmed the importance of sociolinguistic research for the humanities (in this case, for the tourism industry), confirming the hypothesis that advertising names and advertising texts are always pragmatically oriented, since in addition to cognitive and psychoemotional factors, pragmatic stimuli play a large role in their perception.

The results of the experiment showed the effectiveness of project-based learning in the digital environment in terms of interactivity and the introduction of new methods in the educational process: such an approach arouses the students' keen interest, allows them to use and consolidate in practice the theoretical knowledge gained. Control group of the Pushkin State Institute of the Russian Language and the Don State Technical University (Rostov-onDon) (30 people) who participated in the experiment, in the process of intermediate certification, showed a confident command of research methods of sociolinguistics, the ability to reason based on empirical data, as well as an interest in non-standard research tasks.

\section{References}

1. F. Pozzi, J. Asensio-Perez, A. Ceregini, F. Dagnino, et al., Technology pedagogy and education 29(1), 109-128 (2020) doi: 10.1080/1475939X.2020.1714708. 
2. O. Braddick, J. Atkinson, Perception 49(8), 897-899 doi: 10.1177/0301006620943840.

3. L. Gonzalez-Perea, Fernandez Cotan, A. Garcia-Perez, Revista espanola de discapacidad-redis 8(2), 129- 135 (2020) doi: 10.5569/2340-5104.08.02.06.

4. M. Hammad, M. Alnabhan, Abu Doush I., Gonzalez-Perea, Lourdes, et al., International journal of technology and human interaction 16(1), 54-62 (2020) doi: 10.4018/IJTHI.2020010104.

5. M. Nascimento, A. Brandao, L. Brandao, F. Oliveira, IEEE Frontiers in education conference (FIE), (2019).

6. C. Tagliabue, S. Assecondi, G. Cristoforetti, Scientific reports 10(1), 19957 (2020) doi: 10.1038/s41598-020-75297-x.

7. H. Prasetyo, C. Rosyidi, E. Pujiyanto, Cogent engineering 6(1), 1601053 (2019) doi: 10.1080/23311916.2019.1601053.

8. A.N. Bogomolov, Scientific and methodological development of the virtual language environment of distance learning in a foreign language (Russian) the language (Moscow State University, Moscow, 2008)

9. L.A. Dunaeva, G.M. Levina, A.N. Bogomolov, T.V. Vasilyeva, Russian Language Abroad 5, 4-9 (2020)

10. F. Yang, H. Chen, W. Wu, J. Yang, Evaluating the effectiveness of English speaking and learning attitude for elementary students in a digital game-based learning environment, 6th International congress on advanced applied informatics. 569-572 (2017) doi: 10.1109/IIAI-AAI.2017.111.

11. E. Kitanina, D. Trukhanova, Mediaobrazovanie 1, 113-122 (2020)

12. L.M. Goncharova, Advertising communication in the sphere of tourism (INFRA-M, Moscow, 2016)

13. J.M. Swales, Genre analysis: English in academic and research settings (Cambridge University Press, Cambridge, 1990)

14. E.A. Kitanina, D.S. Trukhanova, Journal «Linguo-rhetorical Paradigm: Theoretical and applied aspects» 25(1), 171-174 (2020)

15. L. Cohen, L. Manion, K. Morrison, Research methods in education (6th edition, Routledge, London and New York, 2008)

16. J. Freeman, M. Walters, J. Campbell, How to display data (Bleckwell Publishing, Oxford, 2008).

17. T. Buzen, Intellect-maps. A complete guide to a powerful thinking tool (LLC «Mann, Ivanov and Ferber», Moscow, 2019)

18. N.G. Shved, Innovative teaching methods and their role in improving the quality of higher education, In: Gonarova, L. M. Humanitarian technologies in the modern world. Proceedings of the VI International Scientific and Practical Conference, Kaliningrad, 165-167 (2018)

19. G.M. Bluea, M. Harum, English for Specific Purposes 22, 73-91 (2003)

20. V.P. Malashchenko, Word, word form: the pragmatics of designation. Q: Language. Discourse, Text, Proceedings of the International conference dedicated to the 80th anniversary of Malashchenko V. P., Rostov-on-Don. 7-13 (2004)

21. O.Y. Goykhman, L.M. Goncharova, E.A. Kitanina, T.V. Nesterova, Axiological Approach in The Development of Communicative Competences in University Students, 
In: International Scientific and Practical Conference «Theory and Practice of Project Management in Education: Horizons and Risks», Published online, (2020)

22. O.V. Filippova, Scientific research and development. Modern communication Studies 10(6) (43), 57-62 (2019)

23. T.A. Golikova, TvSU Bulletin, Series «PHILOSOPHY» 4(54), 149-166 (2020)

24. L.M. Goncharova, Modern communication studies 10(1), 83-88 (2021) 